\title{
International Tax Competition in the Global Economy
}

Boris Korneychuk

National Research University Higher School of Economics, Saint-Petersburg, Russia

\begin{abstract}
This study employs a Keynesian-type model of the global economy to investigate the impact of savings rate, openness, and population size on equilibrium tax rates and tax revenues in a world economy. Within the model, the marginal propensity to consume is represented by a matrix specifying each country's income distribution. This study reveals that equilibrium tax rates are higher in countries with a higher rate of savings, greater level of openness, and smaller population size. If an infinitely large number of identical and highly integrated competing countries exist, then a system with indirect taxation has a lower equilibrium tax rate and higher tax revenues than a system with direct taxation. If a country with direct taxation and a country with indirect taxation compete, then the latter country has an advantage.
\end{abstract}

JEL Classifications: E12, F15, F41, H21, H87

Keywords: Tax Competition, Global Economy, Keynesian Model, Tax Policy

\footnotetext{
*Corresponding Author: Boris Korneychuk; Department of Economics, National Research University Higher School of Economics, Saint-Petersburg, Russia, Ulitsa Soyuza Pechatnikov, 16, 190008, Saint-Petersburg, Russia, Tel: +7 9214058701, Fax: 812 7143023, E-mail: bkorneychuk@hse.ru.
} 


\section{Introduction}

The current trends in research on tax competition are marked by an increasingly strong shift from the narrow confines of the standard model of tax competition presented by Zodrow and Mieszkowski (1986) and Wilson (1986). First, the assumption of perfectly mobile real capital is unrealistic as the flow of capital generates initial capital building and transportation costs. In addition, the mobile factor can assume many forms, and each of these forms is subject to different taxes. Many authors have focused on other individual taxes, and only a few models have examined a uniform tax, which characterizes the tax burden in general. Second, the standard model presents a simplified picture of economic interdependence among countries. This problem has been recently addressed in the context of the so-called new economic geography; however, an adequate solution still has not been provided. The usual method based on total import and export evaluations does not consider second-, third-, and higher-order interdependencies reflected in the Leontief input-output model. Third, the standard model of tax competition and its modern modifications ignore the problem of general equilibrium; this decreases the macroeconomic values and prompts the authors to resort to common equilibrium models. The aforementioned trends offer promising prospects for the development of tax competition theory and its integration with general equilibrium theory.

This study aims to take a step in that direction and propose an approach to model tax competition based on the simple Keynesian equilibrium model. Following Keynes, we adopt a pattern of consumer behavior as the main parameter of the model. In our model, the counterpart of the marginal propensity to consume $c$, determines the income allocation between consumption and savings, is the square matrix $C$ indicating the distribution of each country's income among internal consumption, exports, and savings. Simultaneously, the matrix $C$ is the counterpart of the matrix of direct inputs in the Leontief model. Therefore, the matrix multiplier $(I-C)^{-1}$ describes a complex system of interrelations among countries in the global economy and corresponds to the simple Keynesian multiplier in a closed economy $(1-c)^{-1}$. The introduction of a uniform direct tax in all countries results in a new distribution of incomes given by the matrix $(I-T) C$, where $T$ denotes the diagonal matrix with tax rates on the diagonal, while the introduction of a uniform indirect tax generates the matrix $C(I-R)$. Accordingly, two types of multipliers and two cases of equilibrium are produced. A specific state 
of equilibrium is determined by the Nash equilibrium tax rates set by independent governments. It is assumed that the governments maximize the utility function, which is linearly dependent on the volume of private and public goods. Such an approach enables one to consider the income multiplication effect, which is ignored in most modern models of tax competition.

\section{Literature Review}

The basic model of tax competition theory is the model presented by Zodrow and Mieszkowski (1986) and Wilson (1986), which assumes a perfect mobility of physical capital serving as a tax base and target of interregional competition. Edwards and Keen (1996) analyzed the regulatory aspects of tax competition theory. They proposed a view of government as a Leviathan and benevolent maximizer of its citizens' welfare. Furthermore, they concluded that tax competition is harmful and leads to sub-optimally low tax rates. This prevailing view has been shared by many authors. Fuest et al. (2005) concluded that capital tax disappears if real capital is perfectly mobile at the international level. A more recent study by Wilson (1999) indicated that the tendency of tax competition to drive down tax rates can be broken in the case of tax exporting, when the tax rates are inefficiently high. Sorensen (2000) used tax exporting to explain why effective tax rates have not considerably changed in OECD countries with an increase in economic integration.

The standard model of tax competition assumes that each country's public good supply is financed by a tax on the capital employed within its borders. Therefore, some authors have offered a broader view of tax competition. Mendoza et al. (1994) divided all taxes into three categories: capital, labor, and consumption. Sinn (1990) analyzed value-added tax, Klick and Parisi (2005) examined uniform tax and treated GDP as a tax base, and Jacobs et al. (2010) focused on consumption tax. Another drawback of the standard model is that it omits the rate of savings, a key parameter in the Keynesian theory that determines the value of the multiplier and equilibrium macroeconomic variables considerably. Stauvermann and Kumar (2015) allowed for the rate of savings only indirectly through a subjective discount factor in a usual overlapping generations model by Diamond. Modern tax competition research has generally focused on 
individual factors influencing equilibrium tax rates. Bucovetsky (1991) and Wilson (1991) examined the impact of jurisdiction size and demonstrated that smaller regions set lower tax rates. Moreover, Bucovetsky (2009) found that the average tax rate in a federation is determined by a relatively simple index, which must increase as the population distribution becomes more concentrated.

A further strand of literature on tax competition is based on the new economic geography. Ludema and Wooton (2000) demonstrated that international integration may decrease the intensity of tax competition, leading to higher equilibrium tax rates. Such integration may also lead to the spatial agglomeration of economic activities, with divergent economic structures and incomes across countries. Baldwin and Krugman (2004) proposed the theory of agglomeration rent, which rests on the assumption that the lumpiness of an economy gives industrialized nations an advantage over the lessindustrialized nations. Thus, core governments can tax their firms at a higher rate than that at the periphery. Forslid (2005) confirmed the conclusions by Baldwin and Krugman (2004), stating that the effect of openness is important and that it may be nonmonotonic.

A separate line in the development of tax competition theory within the framework of new economic geography involves the use of Leontief's (1936) input-output analysis. Metzler (1951) was the first to discuss the interindustrial price effect of taxes and subsidies in the input-output model. Miyazawa (1966) was one of the first to apply the input-output method to international trade analysis by identifying the export sector of the economy and introducing the concepts of internal and external multipliers. Swenson and Moore (1987) used a set of technical coefficients in the input-output analysis for tax research. They concluded that the major strength of the input-output analysis lies in the fact that it is a general equilibrium model. Borck et al. (2006) described a system of interdependent countries using a matrix of weights based on geographical continuity. Damania et al. (2003) indicated that trade liberalization may have additional beneficial multiplier effects that are usually ignored. Jacobs et al. (2010) examined the effect of a state's spatial characteristics, that is, its size and geographical position. 


\section{The Model}

This part comprises four sections. Section A outlines the model's basic assumptions and briefly discusses the classical closed-economy Keynesian equilibrium model, from which all subsequent models of tax competition in the global economy have been built as a generalization. Section B describes models with a uniform direct tax. It examines tax competition between two countries that are identical in all respects, excluding the following: rate of savings, population size, and level of openness. It shows that the equilibrium tax rate is higher in countries that are richer, have a smaller population size, and have a greater level of openness. Finally, we define the concept of perfect tax competition and examine equilibrium under perfect tax competition. Section $\mathrm{C}$ describes models with a uniform indirect tax. It examines tax competition between two countries that are identical in all respects, excluding the level of openness. It shows that the equilibrium tax rate is higher in countries with a greater level of openness, which is similar to the export tax case. Further, we examine equilibrium under perfect tax competition and compare the equilibrium parameters in different tax systems. We conclude that the import tax system is more favorable for private entrepreneurship; yet, when certain parameters of the utility function are chosen, the equilibrium parameters under perfect tax competition is the same in different systems. Section D proposes an approach to model tax competition using both export and import taxes and describes a model with double taxation.

\section{A. Basics}

The model is based on Keynes's (1936) workhorse model, however, unlike Keynes, we focus on interconnected countries with independent taxing and spending powers. The assumptions of the model are as follows: (1) governments move simultaneously in choosing tax rates; (2) there are two types of government economic policy - to maximize tax revenues (Leviathan) and maximize utility; (3) tax revenues are completely spent on public goods; (4) the utility function is the same for all governments, and it linearly depends on private and public goods; (5) consumption is the only component of autonomous aggregate expenditures; (6) consumption in a country, $e$, equals exogenous autonomous consumption, $c_{a}$, plus variable consumption, which linearly depends 
on incomes in all countries; (7) the tax base equals income, $y$, minus autonomous consumption, in which the latter plays the role of tax deductions; (8) the condition of general equilibrium is the equality of incomes and consumption in each country, where equilibrium incomes depend on tax rates chosen by governments; (9) the reaction function determines the relation between the equilibrium tax rate in one country and the tax rates in other countries; and (10) Nash equilibrium is determined by tax rates that satisfy all reaction functions.

We look at three versions of the global economy model: (1) with an export tax, (2) with an import tax, and (3) with double taxation. In this section, we discuss the classical closed-economy Keynesian model. This is of crucial significance since all subsequent models are generalizations thereof.

As consumption is assumed to be a linear function of disposable income, the equilibrium condition becomes as follows:

$$
y=c_{a}+y(1-t) c
$$

where $y$ denotes the output level of private goods or income, $c_{a}$ denotes autonomous consumption, $c$ denotes the marginal propensity to consume or the rate of consumption, and $t$ denotes the tax rate. Solving equation (1) gives the equilibrium income, $y^{*}$ as follows:

$$
y^{*}=c_{a} m
$$

where * denotes the optimal value, and $m$ denotes the Keynesian tax multiplier:

$$
m=[1-(1-t) c]^{-1}
$$

Tax revenue, $G$, is directly proportional to the tax base, $y-c_{a}$ :

$$
G=t\left(y-c_{a}\right)
$$

Substituting equations (2) and (3) into equation (4) gives the well-known Laffer curve:

$$
G=\frac{c_{a} c\left(t-t^{2}\right)}{s+c t}
$$


where $s$ denotes the marginal propensity to save or the rate of savings, $s=1-c$.

The first case we consider is when the government acts as a Leviathan. Then, the equilibrium first-order condition for the tax revenue in equation (5) gives the equilibrium tax rate:

$$
t_{*}^{1}=\frac{\sqrt{s}-s}{1-s}
$$

where 1 denotes the number of countries in the economic system. We define a country with a lower rate of savings as poor and a country with a higher rate of savings as rich. As Keynes (2008, p. 28) stated, For a poor community will be prone to consume by far the greater part of its output.

The second case is when the government maximizes utility. Following Bucovetsky (2009), we assume that government preferences are linear for both a numeraire private good and public goods. Thus, the utility function for the government, $U$, is given by the following equation:

$$
U=\theta y+G
$$

where $\theta \geq 0$ represents the government's willingness to pursue liberal policies. Thus, it represents the weight given by the government to private goods relative to public goods. We define this parameter as a degree of liberalization. If $\theta=0$, then the government acts as a Leviathan. The equilibrium first-order condition for the utility function in equation (7) gives the equilibrium tax rate:

$$
t_{*}^{1}(\theta)=\frac{\sqrt{s-(1-s) \theta}-s}{1-s}
$$

Three conclusions follow from the equality in equation (8). First, since the derivative of equation (8) with respect to $s$ is positive, the equilibrium tax rate in a rich country is higher than that in a poor country. This conclusion is important if we consider the theory of agglomeration externalities by Baldwin and Krugman (2004). They supposed that the lumpiness gives industrial nations a certain advantage over the less-industrialized nations; thus, core governments can tax their industries at a higher rate than that the periphery. In other words, they considered higher tax rates in the more developed countries to be a result of international trade conditions. Simultaneously, in the classical 
closed-economy Keynesian model, as shown previously, the equilibrium tax rate in rich countries is higher than that in poor ones because of the difference in the rate of savings, and this difference has nothing to do with international trade. Thus, we may consider that the higher tax rate in rich countries is a consequence of the difference in Keynesian multipliers. As the multiplier in a rich country is lower than that in a poor country, the government of the rich country has to compensate for this effect by increasing the tax rate to maximize tax revenues or utility.

Second, using L'Hôpital's rule, we can conclude that if the rate of savings converges to unity, the equilibrium tax rate converges to $0.5-\theta / 2$. In the case of a Leviathan government, it converges to 0.5 . Third, since the derivative of equation (8) with respect to $\theta$ is negative, an increase in the degree of liberalization decreases the equilibrium tax rate and the latter equals zero if $\theta$ exceeds $s /(1-s)$. In other words, the more liberal the government, the lower the tax burden.

\section{B. Model with an export tax}

\section{Settings}

There are two jurisdictions called countries. We assume that a tax is levied on domestic products exclusive of autonomous consumption, that is, on the internal consumption of domestic products and exports. We define such a world economy as a system with an export tax. The basic matrix variables of the model include $Y=\left(y_{1}, y_{2}\right)$; $C_{a}=\left(c_{1}, c_{2}\right) ; C=\left(c_{i j}\right) ; T$ denotes the diagonal matrix with the diagonal $\left(t_{1}, t_{2}\right)$, where $y_{i}$ denotes income, $c_{i}$ denotes autonomous consumption, $t_{i}$ denotes the export tax rate, $c_{i i}$ denotes the share of private output of region $i$ consumed within the country or the rate of internal consumption, $c_{i j}(i \neq j)$ denotes the share of exports from country $i$ to country $j$ in the income of country $i$, and $i=1, \ldots, n$, where $n$ is the number of countries. The matrix $C$ describes the distribution of each country's domestic product between countries in the absence of taxation. The vector $C_{a}$ describes the distribution of population between countries, as we assume that autonomous consumption in each country is directly proportional to population size. Moreover, for the remainder of the paper and without loss of generality, we assume that ci equals the population size of country $i$. We consider the matrix $C$ and the vector $C_{a}$ as exogenously given. The rate of savings in country $i$ is $s_{i}>0, s_{i}=1-c_{i 1}-c_{i 2}$. 
Consumption in country $1, e_{1}$, is the sum of autonomous consumption, $c_{1}$ (term 1 ), the consumption of domestic products after levying export/product taxes in country 1 (term 2 ), and the consumption of imported products, which equals the exports of country 2 after levying export taxes in country 2 (term 3). Consumption in country 2 is the sum of three analogous terms. Thus, the equilibrium condition can be expressed by two equations:

$$
\begin{aligned}
& e_{1}=c_{1}+y_{1}\left(1-t_{1}\right) c_{11}+y_{2}\left(1-t_{2}\right) c_{21} \\
& e_{2}=c_{2}+y_{1}\left(1-t_{1}\right) c_{12}+y_{2}\left(1-t_{2}\right) c_{22}
\end{aligned}
$$

Writing equations (9) and (10) in matrix form yields the following:

$$
E=C_{a}+Y(I-T) C
$$

where $\mathrm{E}=\left(e_{1} e_{2}\right), I$ denotes the identity matrix, and $C$ plays a role in the marginal propensity to consume. The condition of general equilibrium is the equality of income and consumption in each country $(Y=E)$. It is a matrix equivalent to equation (1):

$$
Y=C_{a}+Y(I-T) C
$$

Solving equation (12) gives the vector of equilibrium incomes, $Y^{*}$ :

$$
Y^{*}=C_{a} \times M_{\text {exp }}
$$

where $M_{\text {exp }}$ denotes a matrix tax multiplier or the Leontief inverse, which is the matrix equivalent of the classical multiplier in equation (3).

$$
\begin{gathered}
M_{\text {exp }}=[I-(I-T) C]^{-1} \\
M_{\text {exp }}=\frac{1}{d}\left(\begin{array}{cc}
1-\left(1-t_{2}\right) c_{22} & \left(1-t_{1}\right) c_{12} \\
\left(1-t_{2}\right) c_{21} & 1-\left(1-t_{1}\right) c_{11}
\end{array}\right)
\end{gathered}
$$

where the determinant of the matrix $I-(I-T) C$ is denoted by $d$ : 


$$
d=\left[1-\left(1-t_{1}\right) c_{11}\right] \times\left[1-\left(1-t_{2}\right) c_{22}\right]-\left(1-t_{1}\right)\left(1-t_{2}\right) c_{12} c_{21}
$$

A sufficient condition for the inverse $[I-(I-T) C]^{-1}$ to exist and contain only positive elements is that the sum of the elements of any row of $(I-T) C$ does not exceed unity and that at least one such sum is less than unity. Due to our assumptions, this condition holds true for $C$. Therefore, it also holds true for $(I-T) C$ as all elements of the latter are less than the respective elements of $C$.

\section{A rich country and a poor country}

The world comprises two countries that are identical in all respects, excluding the rate of savings. The governments maximize utility, and $\theta$ is assumed to be the same for both governments. The share of internal consumption of domestic products in each country's income equals the corresponding share of exports: $c_{11}=c_{12}=a>0, c_{21}=c_{22}=b>0, a>$ $b$, and $c_{1}=c_{2}=c_{a}>0$. Since the rate of savings in country 1 is lower than that in country 2 , we define country 1 as poor and country 2 as rich. The world average rate of savings is denoted by $s$, where $s=1-a-b$.

The algorithm for calculating the equilibrium tax rates comprises the following six stages.

Stage 1. The Determinant and Multiplier. Substituting the elements of matrix $C$ into equations (14) and (16) gives the determinant of the matrix $I-(I-T) C$, denoted by $d$, and the multiplier, $M_{\text {exp }}$. Here, the determinant is as follows:

$$
d=s+a t_{1}+b t_{2}
$$

Stage 2. The Income. Substituting the elements of vector $C_{a}$ into equation (13) gives the income of country $1, y_{1}$, as a function of two variable tax rates:

$$
y_{1}=\frac{c_{a}}{s+a t_{1}+b t_{2}}
$$

Stage 3. The Utility or Tax Revenues. Substituting equation (18) into equations (4) and (7) gives the utility in country 1 : 


$$
U_{1}=c_{a} \frac{\theta+t_{1}-s t_{1}^{2}-a t_{1}^{2}-b t_{1} t_{2}}{s+a t_{1}+b t_{2}}
$$

If the governments act as Leviathans, substituting equation (18) into equation (4) gives the tax revenues in country $1, G_{1}$.

Stage 4. The First-Order Condition. The equilibrium tax rate in country 1 satisfies the first-order condition for utility maximization: $\delta U_{1} / \delta t_{1}=0$. It gives the quadratic equation for the equilibrium tax rate 1 , which indirectly defines the reaction function 1 :

$$
a^{2}\left(t_{1}^{*}\right)^{2}+2 a\left(s+b t_{2}\right) t_{1}^{*}-b t_{2}-s(1-s)+b^{2} t_{2}^{2}+\theta=0
$$

If governments act as Leviathans, the first-order condition for maximizing the tax revenue becomes $\delta G_{1} / \delta t_{1}=0$.

Stage 5. The Reaction Function. Solving equation (20) gives the reaction function for country $1, t_{1}^{*}\left(t_{2}\right)$ :

$$
t_{1}^{*}=\frac{1}{a}\left[\sqrt{s+b t_{2}-a \theta}-\left(s+b t_{2}\right)\right]
$$

Working through stages 2 to 5 for country 2 gives the reaction function for country 2 , $t_{2}^{*}\left(t_{1}\right)$ :

$$
t_{2}^{*}=\frac{1}{b}\left[\sqrt{s+a t_{1}-b \theta}-\left(s+a t_{1}\right)\right]
$$

Stage 6. The Nash Equilibrium. Since the Nash equilibrium is the intersection of reaction functions, solving the system of reaction functions gives the equilibrium tax rates $t_{1}^{*}$ and $t_{2}^{*}$. Solving the systems represented by equations (21) (22) gives the following equation:

$$
\frac{t_{2}^{*}}{t_{1}^{*}}=\frac{a}{b}+\left(\frac{a}{b}-1\right) \frac{\theta}{t_{1}^{*}}
$$

This implies that (1) the equilibrium tax rate in a rich country is higher than that in a poor country, as in the classical Keynesian model; (2) an increase in the degree of liberalization of economic policy increases the difference between tax rates in rich and poor countries; and (3) if the governments act as Leviathans, then $t_{2}{ }^{*} / t_{1}{ }^{*}=a / b$. 
Suppose the governments act as Leviathans. Substituting $\theta=0$ into equation (21) gives the reaction function for country 1 :

$$
t_{1}^{*}=\frac{1}{a}\left[\sqrt{s+b t_{2}}-\left(s+b t_{2}\right)\right]
$$

Differentiating equation (24) with respect to $t_{2}$ gives the following:

$$
\frac{\delta t_{1}^{*}}{\delta t_{2}}=\frac{b\left(1-2 \sqrt{s+b t_{2}}\right)}{2 a \sqrt{s+b t_{2}}}
$$

Setting the right-hand side of equation (25) to zero gives a tax rate $t_{2}^{0}$, which divides the upward-sloping and downward-sloping sections of the reaction function, $t_{2}^{0}=(1-4 s) / 4 a$. This implies that if the rate of savings exceeds 0.25 , then the reaction functions have no upward-sloping section. If the rate is less than 0.25 , then the reaction functions have upward and downward-sloping sections. The presence of both upward and downward-sloping sections can be accounted for by the hypothesis that the two following effects exist. Because of the substitution effect, a higher tax rate in country 2 makes country 1 relatively richer and induces the government of the latter to increase its tax rate. Because of the income effect, a higher tax rate in country 2 makes all countries, including country 1 , poorer and induces the government of the latter to decrease its tax rate. The resulting tax rate is the outcome of balancing these two effects. If the substitution effect outweighs the income effect, then the tax rate in country 1 increases with the tax rate in country 2 and the reaction function is upward sloping. This is possible if $s<0.25$ and $t_{2}<t_{2}{ }^{0}$. If the income effect outweighs the substitution effect, then the tax rate in country 1 decreases with the higher tax rate in country 2 and the reaction function is downward sloping. This is possible if $s>0.25$ or $t_{2}>t_{2}{ }^{0}$.

\section{A large country and a small country}

The world comprises two countries that are identical in all respects, excluding population size: $c_{i j}=a>0, i, j=1,2$. The governments act as Leviathans. The population size of country $1, c_{1}$, is a variable, and the population size of country $2, c_{2}$, is exogenously given, $l=\frac{c_{2}}{c_{1}}$. Working through stages $1 \sim 5$ gives the income, tax revenues, first-order condition, and reaction function for country 1 : 


$$
\begin{gathered}
y_{1}=c_{1} \frac{1-a(1-l)\left(1-t_{2}\right)}{s+a t_{1}+a t_{2}} \\
G_{1}=c_{1} a \frac{t_{1}+l t_{1}-t_{1}^{2}-l t_{1} t_{2}}{s+a t_{1}+a t_{2}} \\
a\left(t_{1}^{*}\right)^{2}+2\left(s+a t_{2}\right) t_{1}^{*}-(a l+a-l s+2 s) t_{2}-s(1+l)+a l t_{2}^{2}=0 \\
t_{1}^{*}=\frac{1}{a}\left[\sqrt{a^{2}(1-l) t_{2}^{2}+a(2 s+a l-l s+a) t_{2}+s(s+a+a l)}-s-a t_{2}\right]
\end{gathered}
$$

Differentiating the reaction function in equation (29) with respect to $l$ gives the following:

$$
\frac{\delta t_{1}^{*}}{\delta l}=\frac{-a t_{2}^{2}+(a-s) t_{2}+s}{2 \sqrt{\ldots}}
$$

The numerator in the right-hand side of equation (30) is positive since it is a product of two positive multipliers: $\left(1-t_{2}\right)\left(s+a t_{2}\right) \geq 0$. As both the numerator and denominator in the right-hand side of equation (30) are positive, the derivative in the left-hand side is positive as well. This means that an increase in the population size of country 1 (a decrease in $l$ ) decreases the equilibrium tax rate in country 1 . Consequently, the reaction function for country 1 in Figure 1 shifts to the left.

Working through stages $1 \sim 5$ for country 2 gives the reaction function for country 2 :

$$
t_{2}^{*}=\frac{1}{a}\left[\sqrt{a^{2}\left(1-\frac{1}{l}\right) t_{1}^{2}+a\left(2 s+\frac{a-s}{l}+a\right) t_{1}+s\left(s+a+\frac{a}{l}\right)}-s-a t_{1}\right]
$$

Differentiating the reaction function in equation (31) with respect to $l$ gives the following:

$$
\frac{\delta t_{2}^{*}}{\delta l}=\frac{a t_{1}^{2}-(a-s) t_{1}-s}{2 l^{2} \sqrt{\ldots}}
$$


The numerator in the right-hand side of equation (32) is negative, while the denominator is positive. Therefore, the derivative in the left-hand side is negative. This means that an increase in the population size of country 1 (a decrease in $l$ ) increases the equilibrium tax rate in country 2. Consequently, the reaction function for country 2 in Figure 1 shifts upwards.

\section{Figure 1. A smaller country levies a higher tax rate}

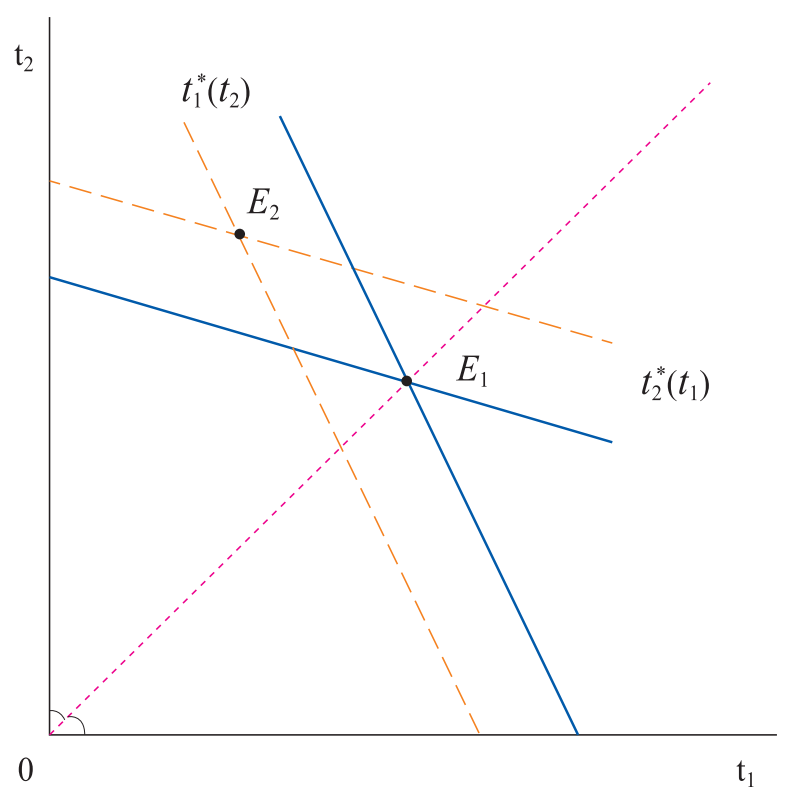

(Note) The equilibrium tax rates are equal and the point of Nash equilibrium is denoted by $E_{1}$. As the population size of country 1 increases, the reaction function 1 shifts to the left and the reaction function 2 shifts upwards. The intersection of the broken lines $E_{2}$ marks the new point of Nash equilibrium.

(Source) Author's creation

Suppose that in the initial state, the countries' population size is the same. Then, by symmetry, the equilibrium tax rates are equal and the point of Nash equilibrium is denoted by $E_{1}$. As the population size of country 1 increases, the reaction function 1 shifts to the left and the reaction function 2 shifts upwards. The intersection of the broken lines $E_{2}$ marks the new point of Nash equilibrium (Figure 1). This indicates that an increase in the population size of country 1 relative to country 2 decreases the equilibrium tax rate in country 1 and increases the equilibrium tax rate in country 2 . 
Therefore, a smaller country sets a higher tax rate. This contradicts the conclusion drawn by Bucovetsky (1991), who demonstrated that in a model of capital tax competition, the smaller jurisdiction levies a lower tax rate.

\section{A highly integrated country and a loosely integrated country}

The world comprises two countries that are identical in all respects, excluding the share of exports in their incomes, which characterizes the level of openness of the respective economies. Our choice of this measure of openness is motivated by two reasons. First, the share of exports characterizes the comparative advantage of a country's economy and largely determines the potential value of imports. This enables us to ignore the share of imports, whereas a common approach, starting with the study by Garrett (1995), considers total exports and imports as a measure of openness. Second, there is a negative relation between the share of exports and trade costs, which determine the degree of openness in the theory of agglomeration advantages by Baldwin and Krugman (2004). This relation suggests that the share of exports could depend on trade costs, along with other factors of openness.

We consider the governments to act as Leviathans and assume that the share of exports in one country's income equals the other country's rate of internal consumption: $c_{11}=c_{21}=a>0, c_{12}=c_{22}=b>0$, where $a \leq b$ and $c_{1}=c_{2}=c_{\mathrm{a}}$.

Since the share of exports in country 1 is higher than that in country 2, country 1's level of integration into the world economy is relatively greater than that of country 2 . Thus, we define country 1 as highly integrated and country 2 as loosely integrated.

Working through stages 1 to 5 gives the income, tax revenues, and indirectly defined reaction function for country 1 :

$$
\begin{gathered}
y_{1}=c_{a} \frac{1-(b-a)\left(1-t_{2}\right)}{s+a t_{1}+b t_{2}} \\
G_{1}=a c_{a} \frac{2 t_{1}-t_{1}^{2}-t_{1} t_{2}}{s+a t_{1}+b t_{2}} \\
a\left(t_{1}^{*}\right)^{2}+2\left(s+b t_{2}\right) t_{1}^{*}+(s-2 b) t_{2}-2 s+b\left(t_{2}\right)^{2}=0
\end{gathered}
$$

Working through stages 1 to 5 for country 2 gives the indirectly defined reaction function for country 2 : 


$$
b\left(t_{2}^{*}\right)^{2}+2\left(s+a t_{1}\right) t_{2}^{*}+(s-2 a) t_{1}-2 s+a\left(t_{1}\right)^{2}=0
$$

Substituting variable tax rates into the equilibrium tax rates and subtracting equation (35) from equation (36) gives the difference between the equilibrium tax rates:

$$
t_{1}^{*}-t_{2}^{*}=\frac{2(b-a) t_{2}^{*}\left(1-t_{2}^{*}\right)}{2(b-a) t_{2}^{*}+2 a+s}
$$

The right-hand side of equation (37) is positive. Therefore, in the system with an export tax, the equilibrium tax rate in a highly integrated country is higher than that in a loosely integrated country. Technically, this result corresponds to the theory of agglomeration rent by Baldwin and Krugman (2004). However, the causes of the difference between the equilibrium tax rates are different. Since commodity exporters tend to be highly integrated and less-industrialized countries, they cannot be classified as core nations.

\section{Perfect tax competition}

Tax competition is defined as perfect if the world comprises many independent identical countries: $c_{i j}=a>0$, where $c_{i}=c_{a}$ and $i, j=1, \ldots, n$, where $n$ is the number of countries. The share of internal consumption in each country, $c_{i i}=(1-s) / n$, converges to zero as the number of countries becomes infinitely large. Therefore, perfect tax competition describes the case with the highest degree of trade integration.

First, we consider the case in which the governments act as Leviathans and wherein the world comprises three identical countries. We then apply the model to the case of an unlimited number of countries. Working through stages $1 \sim 2$ gives the income of country 1 :

$$
y_{1}=\frac{c_{a}}{s+a t_{1}+a t_{2}+a t_{3}}
$$

where $s=1-3 a$. As can be seen from equation (38), the incomes of identical countries are always equal, being determined by a common function that only depends on the world average tax rate. Simultaneously, a country with a higher tax rate gets larger tax revenues. Therefore, each country is interested in increasing its tax rate. Working through stages 3 to 4 gives the tax revenues and first-order condition for country 1 : 


$$
\begin{gathered}
G_{1}=c_{a} \frac{t_{1}-s t_{1}-a t_{1}^{2}-a t_{1} t_{2}-a t_{1} t_{3}}{s+a t_{1}+a t_{2}+a t_{3}} \\
a\left(t_{1}^{*}\right)^{2}+2(s+a T) t_{1}^{*}-\frac{s(1-s)}{a}+2 s T-T+a T^{2}=0
\end{gathered}
$$

where $T=t_{2}+t_{3}$. We now apply equation (40) to a world with $\mathrm{n}$ countries, $n=k+1$ :

$$
a t_{*}^{2}+2\left(s+a k t_{*}\right) t_{*}-\frac{s(1-s)}{a}+2 s k t_{*}-k t_{*}+a k^{2} t_{*}^{2}=0
$$

Solving equation (41) gives the equilibrium tax rate:

$$
t_{*}^{k+1}=\frac{\sqrt{4 s+4 k s+k^{2}}-2 s-2 k s+k}{2(1+k)(1-s)}
$$

Using L'Hôpital's rule, we conclude that if $s$ converges to 1 , the equilibrium tax rate converges to $(k+1) /(k+2)$. Hence, in a closed economy $(k=0)$, the maximum equilibrium tax rate equals 0.5 . It equals 0.666 in a system with two countries and converges to 1 in the case of unlimited number of countries. Solving equation (40) gives the function of the equilibrium tax rate in country 1, which only depends on the sum of tax rates of $\mathrm{k}$ other countries; an equivalent of the reaction function:

$$
t_{1}^{*}(T)=\frac{1}{a}[\sqrt{s+a T}-(s+a T)]
$$

where $T=t_{2}+\cdots+t_{n}$. Differentiating equation (43) with respect to $t_{j}$ gives the following:

$$
\frac{\delta t_{i}^{*}}{\delta t_{j}}=\frac{1-2 \sqrt{s+a T}}{2 \sqrt{s+a T}}
$$

where $i \neq j$. Equation (44) implies that the derivative of the equilibrium tax rate in one country with respect to the tax rate in any other country depends only on the sum of tax rates in other countries. The derivative is positive if the average tax rate of other 
countries is lower than $t^{0}$ :

$$
t^{0}=\frac{(1-4 s)(k+1)}{4(1-s) k}
$$

Equation (45) illustrates that the positive relation between the equilibrium tax rate in a given country and the tax rate in any other country is possible if the rate of savings is less than 0.25 , as in the case of two countries.

Similarly, we can study the case of utility maximization for a large number of identical countries. It can be shown that the equilibrium tax rate becomes as follows:

$$
t_{*}^{k+1}(\theta)=\frac{\sqrt{4 s+4 k s+k^{2}-4(k+1)(1-s) \theta}-2 s-2 k s+k}{2(1+k)(1-s)}
$$

Applying L'Hôpital's rule, we see that equation (46) gives the equilibrium tax rate under perfect tax competition, $n \rightarrow \infty$ :

$$
t_{*}^{\infty}=1-\theta
$$

Using equation (38), we obtain the equilibrium income for the case of $n$ countries:

$$
y_{*}^{n}=\frac{c_{a}}{s+(1-s) t_{*}^{n}}
$$

Using equations (47) and (48), we get the equilibrium income under perfect tax competition:

$$
y_{*}^{\infty}=\frac{c_{a}}{1-\theta(1-s)}
$$

Substituting equation (49) into equation (4) gives the equilibrium tax revenue under perfect tax competition:

$$
G_{*}^{\propto}=\frac{c_{a}(1-\theta) \theta(1-s)}{1-\theta(1-s)}
$$


Equations (47) (50) imply that under perfect tax competition in a system with an export tax, (1) the equilibrium tax rate depends only on the degree of liberalization, whereas the equilibrium income and tax revenues depend on the rate of savings and population size; (2) if the government values private goods in the same manner as public goods $(\theta=1)$, then the equilibrium tax rate is zero; and (3) in the Leviathan case $(\theta=0)$, the equilibrium tax rate converges to 1 , the income converges to autonomous consumption, and the tax revenues converge to zero. Thus, if each country seeks to maximize its tax revenues, then the equilibrium tax revenue of each country converges to zero. This effect is similar to the paradox of thrift in Keynesian theory. If society attempts to save more, it may end up actually saving the same amount or even less. This result is consistent with the conclusion reached by Wilson and Wildasin (2004) that Leviathan models and the Zodrow-Mieszkowski model agree that tax competition lowers the size of government.

Differentiating equation (50) with respect to $\theta$ gives the degree of liberalization $\theta_{\text {exp }}$, which maximizes the equilibrium tax revenue under perfect tax competition:

$$
\theta_{\exp }=\frac{1-\sqrt{s}}{1-s}
$$

This rate of liberalization allows governments to reach a certain compromise between two goals of economic policy: encouraging private business $(\theta \neq 0)$ and providing people with public goods $(G \neq 0)$. Substituting equation (51) into equations (49) and (50) gives the equilibrium income and equilibrium tax revenues for the case when $\theta=\theta_{\text {exp }}$ :

$$
\begin{gathered}
y_{*}^{\infty}\left(\theta_{\text {exp }}\right)=\frac{c_{a}}{\sqrt{s}} \\
G_{*}^{\infty}\left(\theta_{\text {exp }}\right)=c_{a} \frac{1-\sqrt{s}}{s+\sqrt{s}}
\end{gathered}
$$

\section{Model with an import tax}

\section{Settings}

The world comprises two identical countries. Taxes are levied on consumption exclusive 
of autonomous consumption, that is, on the internal consumption of domestic products and imports. Such a world economy is defined as a system with an import tax. Basic matrix variables of the model include $Y=\left(y_{1}, y_{2}\right) ; C_{a}=\left(c_{1}, c_{2}\right) ; C=\left(c_{i j}\right)$; and $R$ is a diagonal matrix with the diagonal $\left(\tau_{1}, \tau_{2}\right)$, where $\tau_{1}$ is the import tax rate. Consumption in country $1, e_{1}$, is the sum of autonomous consumption, $c_{1}$ (term 1 ), the consumption of domestic products after levying import/product taxes in country 1 (term 2), and the consumption of imported products, which equals the exports of country 2 after levying import taxes in country 1 (term 3). Consumption in country $2, e_{1}$, is the sum of three analogous terms. Thus, the equilibrium condition is determined by two equations:

$$
\begin{aligned}
& e_{1}=c_{1}+y_{1}\left(1-\tau_{1}\right) c_{11}+y_{2}\left(1-\tau_{1}\right) c_{21} \\
& e_{2}=c_{2}+y_{1}\left(1-\tau_{2}\right) c_{12}+y_{2}\left(1-\tau_{2}\right) c_{22}
\end{aligned}
$$

Equations (57) and (58) can be written in a matrix form as follows:

$$
E=C_{a}+Y C(I-R)
$$

The condition of general equilibrium is the equality of income and consumption in each country:

$$
Y=C_{a}+Y C(I-R)
$$

Solving equation (57) gives the vector of equilibrium incomes, $Y^{*}$, and the matrix multiplier for the system with an import tax, $M_{i m p}$ :

$$
\begin{gathered}
Y^{*}=C_{a} \times M_{i m p} \\
M_{i m p}=[I-C(I-R)]^{-1} \\
M_{i m p}=\frac{1}{d}\left(\begin{array}{cc}
1-\left(1-\tau_{2}\right) c_{22} & \left(1-\tau_{2}\right) c_{12} \\
\left(1-\tau_{1}\right) c_{21} & 1-\left(1-\tau_{1}\right) c_{11}
\end{array}\right) \\
d=\left[1-\left(1-\tau_{1}\right) c_{11}\right] \times\left[1-\left(1-\tau_{2}\right) c_{22}\right]-\left(1-\tau_{1}\right)\left(1-\tau_{2}\right) c_{12} c_{21}
\end{gathered}
$$


where $d$ is the determinant of the matrix $I-C(I-R)$.

\section{A highly integrated country and a loosely integrated country}

The world comprises two countries that are identical in all respects, excluding the share of exports in their income, which characterizes the level of openness of the respective economies. The governments act as Leviathans. The share of exports in one country's income equals the other country's rate of internal consumption: $c_{11}=c_{21}=a>$ $0, c_{12}=c_{22}=b>0$, where $a \leq b$ and $c_{1}=c_{2}=c_{a}$. We define country 1 as highly integrated and country 2 as loosely integrated.

Working through stages 1 to 5 gives the income, tax revenues, and indirectly defined reaction function for country 1 :

$$
\begin{gathered}
y_{1}=c_{a} \frac{1+a-b-a \tau_{1}+b \tau_{2}}{s+a \tau_{1}+b \tau_{2}} \\
G_{1}=2 a c_{a} \frac{\tau_{1}-\tau_{1}^{2}}{s+a \tau_{1}+b \tau_{2}} \\
a\left(\tau_{1}^{*}\right)^{2}+2 s \tau_{1}^{*}+2 b \tau_{1}^{*} \tau_{2}-b \tau_{2}-s=0
\end{gathered}
$$

Substituting $\tau_{2}=0$ into equation (64) gives the quadratic equation for $\tau_{1}^{*}(0)$

$$
a\left[\tau_{1}^{*}(0)\right]^{2}+2 s \tau_{1}^{*}(0)-s=0
$$

This determines the point of intersection of the reaction function 1 and the horizontal axis:

$$
\tau_{1}^{*}(0)=\frac{1}{1-b-s}(\sqrt{s(1-b)}-s)
$$

Suppose that $s$ is exogenously given. Then, the shifts of the reaction functions depend only on the variable share of exports in the income of country 1 (or the share of internal consumption in the income of country 2 ) $-b$. Differentiating equation (66) with respect to $b$ gives the following: 


$$
\frac{\delta \tau_{1}^{*}(0)}{\delta b}=S \frac{\frac{s+(1-b)}{2}-\sqrt{s(1-b)}}{(1-b-s)^{2} \sqrt{s(1-b)}}
$$

The numerator in the right-hand side of equation (67) is positive since the arithmetic means of $s$ and $(1-b)$ exceed their geometric means. As both the numerator and denominator are positive, the derivative is positive as well. This means that an increase in the share of exports in the income of country 1 increases the equilibrium tax rate in country 1 if $\tau_{2}$ equals zero. It is evident that the reaction function 1 in Figure 2 shifts to the right.

Similarly, the indirectly determined reaction function 2 becomes as follows:

$$
b\left(\tau_{2}^{*}\right)^{2}+2 s \tau_{2}^{*}+2 a \tau_{2}^{*} \tau_{1}-a \tau_{1}-s=0
$$

Substituting $\tau_{1}=0$ into equation (68) gives the quadratic equation for $\tau_{2}^{*}(0)$ :

\section{Figure 2. A highly integrated country levies a higher tax rate}

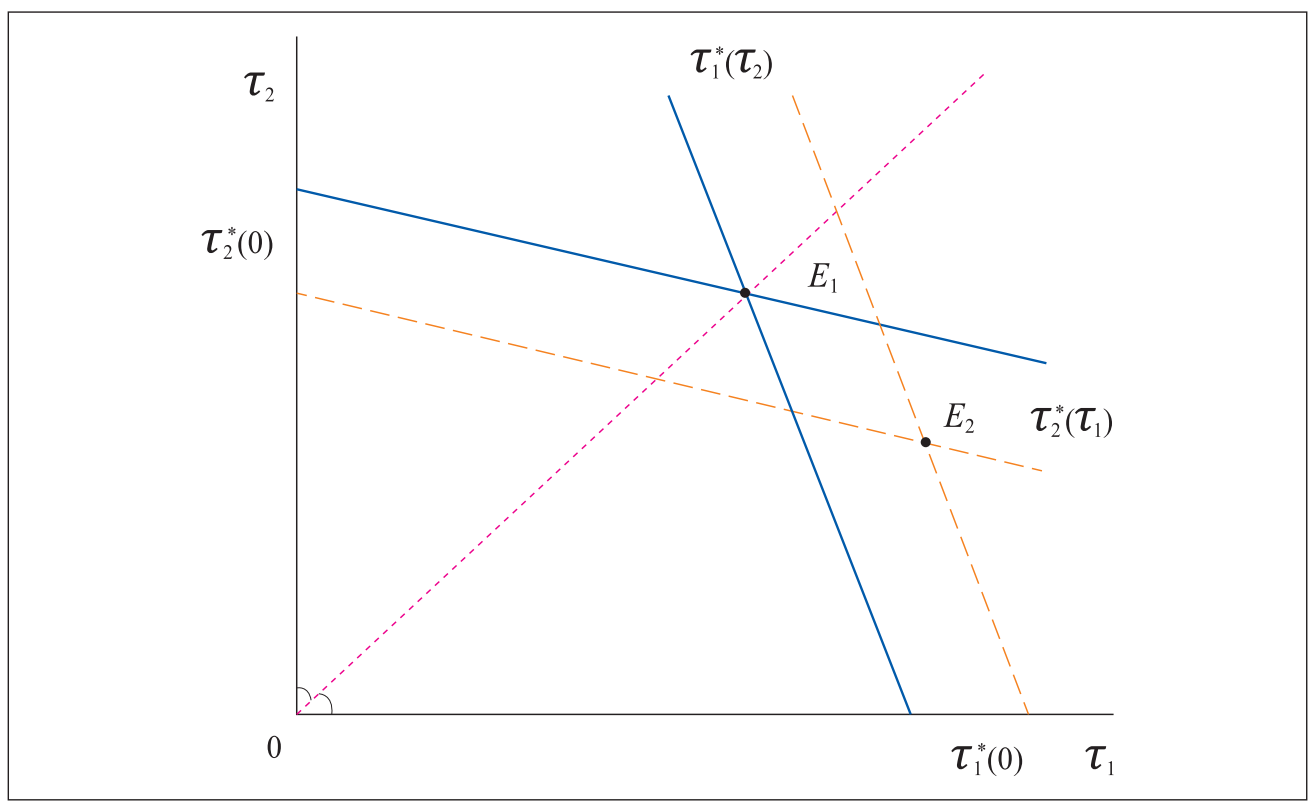

(Note) Suppose that in the initial state, each country's share of exports equals the share of internal consumption. Then, the equilibrium tax rates are equal, and the point of Nash equilibrium is denoted by $E_{1}$. Suppose that the share of exports in country 1 increases. Then, the reaction function 1 shifts to the right, and the reaction function 2 shifts downwards. The intersection of the broken lines $E_{2}$ marks the new point of Nash equilibrium.

(Source) Author's creation 


$$
b\left[\tau_{2}^{*}(0)\right]^{2}+2 s \tau_{2}^{*}(0)-s=0
$$

This determines the point of intersection of the reaction function 2 and the vertical axis:

$$
\tau_{2}^{*}(0)=\frac{1}{b}(\sqrt{s(s+b)}-s)
$$

Differentiating equation (70) with respect to $b$ gives the following:

$$
\frac{\delta \tau_{2}^{*}(0)}{\delta b}=s \frac{\sqrt{s(s+b)}-\frac{s+(s+b)}{2}}{b^{2} \sqrt{s(s+b)}}
$$

The numerator in the right-hand side of equation (71) is negative since the arithmetic means of $s$ and $(s+b)$ exceed their geometric means. As the denominator is positive, the derivative is negative. This means that an increase in the share of exports in the income of country 1 decreases the tax rate in country 2 if $\tau_{1}$ equals zero. It is evident that the reaction function 2 in Figure 2 shifts downwards.

Suppose that in the initial state, each country's share of exports equals the share of internal consumption. Then, the equilibrium tax rates are equal, and the point of Nash equilibrium is denoted by $E_{1}$. Suppose that the share of exports in country 1 increases. Then, the reaction function 1 shifts to the right, and the reaction function 2 shifts downwards. The intersection of the broken lines $E_{2}$ marks the new point of Nash equilibrium in Figure 2. It shows that an increase in the share of exports in country 1 (highly integrated) decreases the equilibrium tax rate in country 2 (loosely integrated) and increases the equilibrium tax rate in country 1 . Therefore, in a system with an import tax, a highly integrated country sets a higher tax rate. Thus, a highly integrated country would levy a higher tax rate both in the system with an export tax and in the system with an import tax.

\section{Perfect tax competition}

We first explain the difference in the behavior of identical countries in a system with an export tax and a system with an import tax. Substituting $b$ with a in equation (62) gives an analogous equation for the income in country 2. Subtracting these equations gives the difference between their incomes in a system with an import tax: 


$$
y_{1}-y_{2}=2 c_{a} a \frac{\tau_{2}-\tau_{1}}{s+a\left(\tau_{1}+\tau_{2}\right)}
$$

Equation (72) implies that income in a country with a higher tax rate is relatively lower; thus, an increase in the tax rate decreases income and the tax base compared with the situation in a country with a constant tax rate. Therefore, as opposed to the model with an export tax, a country is not interested in indefinitely increasing its tax rate. Now, consider the Leviathan case with three identical countries and then apply the model to a world with $n=k+1$ countries:

$$
a \tau_{*}^{2}+2\left(s+a k \tau_{*}\right) \tau_{*}-s-a k \tau_{*}=0
$$

Solving equation (73) gives the equilibrium tax rate as follows:

$$
\tau_{*}^{k+1}=\frac{\sqrt{[k(1+s)+2 s]^{2}+4 s(1-s)(k+1)}-2 s-3 k s+k}{2(1+2 k)(1-s)}
$$

Next, consider the case in which governments maximize utility under perfect tax competition. The equilibrium tax rate in country 1 can be shown to take the following form:

$$
\tau_{*}^{k+1}=\frac{\sqrt{k^{2}[2 s+(1-s)(1-\theta)]^{2}+8 s-8 s^{2}}-2 s k-2 s+(1-s) k(1-\theta)}{2(1+2 k)(1-s)}
$$

Application of L'Hôpital's rule to equation (75) gives the equilibrium tax rate under perfect tax competition, $n \rightarrow \infty$ :

$$
\tau_{*}^{\infty}(\theta)=\frac{1}{2}-\frac{\theta}{2}
$$

Note that this value equals the equilibrium tax rate in the Keynesian model of a closed economy for the case of a perfect rich country. When the rate of consumption, c, converges to zero. In the model with an import tax, the same value of the equilibrium tax rate holds for the case of perfect integration when the rate of internal consumption, $c_{i i}=$ $a=1 / n(\mathrm{i}=1, \ldots, n)$, converges to zero. Thus, the rate of internal consumption measures both the richness of a country and its degree of openness.

Using equations (58), (60), (61), and (76), we get the equilibrium income under perfect 
tax competition:

$$
y_{*}^{\infty}=\frac{2 c_{a}}{1+s-\theta(1-s)}
$$

Substituting equation (76) into equation (4) gives the equilibrium tax revenues under perfect tax competition:

$$
G_{*}^{\infty}=\frac{c_{a}\left(1-\theta^{2}\right)(1-s)}{2[1+s-\theta(1-s)]}
$$

Equations (76) (78) imply that under perfect tax competition in a system with an import tax, (1) the equilibrium tax rate depends only on the degree of liberalization, whereas the equilibrium income and tax revenues depend on the rate of savings and population size, which is similar to the system with an export tax; (2) if the government values private goods in the same manner as public goods $(\theta=1)$, then the equilibrium tax rate is zero, which is similar to the system with an export tax; and (3) in the Leviathan case $(\theta=0)$, the equilibrium tax rate converges to 0.5 , the income exceeds autonomous consumption, and the tax revenues are positive.

Equations (46) and (75) indicate that in both tax systems, the equilibrium tax rate increases with the number of countries. This conclusion is consistent with the empirical results obtained by Bretschger and Hettich (2005), who indicated that globalization negatively impacts capital tax rates.

Differentiating equation (78) with respect to $\theta$ gives the degree of liberalization $\theta_{\text {imp }}$, which maximizes the equilibrium tax revenues under perfect tax competition:

$$
\theta_{i m p}=\frac{1+s-2 \sqrt{s}}{1-s}
$$

This rate of liberalization allows governments to reach a certain compromise between two goals of economic policy. Substituting equation (79) into equations (77) and (78) gives the equilibrium income and equilibrium tax revenues for the case when $\theta=\theta_{\text {imp }}$ :

$$
y_{*}^{\infty}\left(\theta_{i m p}\right)=\frac{c_{a}}{\sqrt{s}}
$$




$$
G_{*}^{\infty}\left(\theta_{i m p}\right)=c_{a} \frac{1-\sqrt{s}}{s+\sqrt{s}}
$$

Comparing equations (51) and (79), we see that $\theta_{\text {exp }}$ exceeds $\theta_{\text {imp. }}$. Comparing equations (52) and (80) as well as equations (53) and (81), we conclude that if the government chooses the optimal value of $\theta$ to maximize its tax revenues under perfect tax competition, then the equilibrium values of income and tax revenues will equal. In this case, basic macroeconomic variables do not depend on the type of taxes in the world economy.

\section{Model with double taxation}

We now consider a model that describes a world in which each country can levy both export and import taxes. We focus on the case where country 1 levies an export tax and country 2 levies an import tax. In this case, exports from country 1 are subject to double taxation. The governments act as Leviathans. Suppose that the countries are identical: $c_{i j}=a ; c_{i}=c_{a}(i=1,2) ; T$ is a diagonal matrix with the diagonal $\left(t_{1}, 0\right)$; and $R$ is a diagonal matrix with the diagonal $\left(0, \tau_{2}\right)$, where $t_{1}$ denotes the export tax rate in country 1 and $\tau_{2}$ denotes the import tax rate in country 2 . Then, the vector of equilibrium incomes, $Y^{*}$, and full multiplier, $M_{f}$, become as follows:

$$
\begin{gathered}
Y^{*}=C_{a} \times M_{f} \\
M_{f}=[I-(I-T) C(I-R)]^{-1} \\
M_{f}=\frac{1}{d}\left(\begin{array}{cc}
1-\left(1-\tau_{2}\right) a & \left(1-t_{1}\right)\left(1-\tau_{2}\right) a \\
a & 1-\left(1-t_{1}\right) a
\end{array}\right)
\end{gathered}
$$

where $d$ denotes the determinant of the matrix $I-(I-T) C(I-R), d=s+a t_{1}+a \tau_{2}$. Working through stages $1 \sim 5$ gives the income, tax revenues, and the reaction function for country 1 :

$$
y_{1}=c_{a} a \frac{1+a \tau_{2}}{s+a t_{1}+a \tau_{2}}
$$




$$
\begin{gathered}
G_{1}=c_{a} a \frac{2 t_{1}-t_{1}^{2}}{s+a t+a \tau_{2}} \\
t_{1}^{*}=\frac{1}{a}\left(\sqrt{\left(s+a \tau_{2}\right)\left(1+a \tau_{2}\right)}-s-a \tau_{2}\right)
\end{gathered}
$$

Differentiating equation (87) with respect to $\tau_{2}$ gives the following:

$$
\frac{\delta t_{1}^{*}}{\delta \tau_{2}}=\frac{\frac{\left(s+a \tau_{2}\right)+\left(1+a \tau_{2}\right)}{2}-\sqrt{\left(s+a \tau_{2}\right)\left(1+a \tau_{2}\right)}}{\sqrt{\ldots}}
$$

The numerator in the right-hand side of equation (88) is positive since the arithmetic mean is greater than the geometric mean. As both the numerator and denominator are positive, the derivative in the left-hand side is positive as well. This means that the reaction function 1 is upward sloping, unlike the case of two identical countries that levy a tax of the same type. Similarly, the income of country 2 becomes as follows:

$$
y_{2}=c_{a} a \frac{1-a\left(1-t_{1}\right) \tau_{2}}{s+a t_{1}+a \tau_{2}}
$$

Comparing equations (85) and (89), we see that $y_{1}$ always exceeds $y_{2}$, and thus, the tax base 1 always exceeds the tax base 2 . The reaction function for country 2 becomes as follows:

$$
\tau_{2}^{*}=\frac{1}{a}\left(\sqrt{\left(s+a t_{1}\right)\left(1-a+a t_{1}\right)}-s-a t_{1}\right)
$$

Using equations (87) and (90) gives the following proportion:

$$
\frac{s+a \tau_{2}^{*}}{s+a t_{1}^{*}}=\frac{1-a+a t_{1}^{*}}{1+a \tau_{2}^{*}}
$$

Assume that $\tau_{2}^{*}$ exceeds $t_{1}^{*}$. Then, the left-hand side of equation (91) exceeds unity, but the right-hand side is less than unity. This leads to a contradiction, and therefore, $t_{1}^{*}$ exceeds $\tau_{2}^{*}$. We have shown that the tax base 1 exceeds the tax base 2 . Therefore, the equilibrium tax revenue in country 1 exceeds that in country 2 . Thus, if imports in one country are subject to double taxation, then its equilibrium tax rate, income, and tax revenues are lower than those in another country. 


\section{Conclusion}

This study shows that the integration of the simple Keynesian equilibrium model with tax competition theory enables one to create a Keynesian-type macroeconomic model. This is a useful tool to investigate the factors influencing the equilibrium tax rates in different tax systems. While the rate of savings is almost ignored in tax competition models, we show its positive relation with the equilibrium tax rate, confirming that the tax burden in rich countries is higher than that in poor ones. We also demonstrate that the tax burden is higher in more open countries as opposed to less open ones. As highly industrialized core nations are characterized by a high rate of savings and a high level of openness, these two findings together serve as an additional argument in favor of the familiar statement by Baldwin and Krugman(2004); the core countries face higher equilibrium tax rates than the periphery countries.

The analysis has produced several unexpected findings. First, in contrast to Bucovetsky's results, our study indicates that the equilibrium tax rates are higher in small countries than those in large ones. This inconsistency can be attributed to the fact that we examine taxation with a positive tax deduction. As large countries have higher tax deductions, the tax base and equilibrium tax rate will be relatively lower than those under proportional taxes. Second, this study demonstrates that in the case of identical countries with a high level of openness, the equilibrium tax rate increases with the number of competing countries. This result is in opposition to the common belief that increasing tax competition decreases equilibrium tax rates. Third, our study shows that in the long run, the economic conditions in a system with protective import taxes can turn out to be more favorable for business and government than those in a system with export taxes.

Received 9 October 2017, Revised 24 October 2017, Accepted 13 November 2017 


\section{References}

Baldwin, Richard and Krugman, Paul. "Agglomeration, Integration and Tax Harmonization.” European Economic Review 48 (2004): 1-23.

Borck, Rainald, Caliendo, Marco and Steiner, Viktor. "Fiscal Competition and the Composition of Public Spending: Theory and Evidence." FinanzArchiv Public Finance Analysis 63 no.2 (2007): 264-277, http://www.jstor.org/stable/40913149.

Bretschger, Lucas and Hettich, Frank. "Globalization and International Tax Competition: Empirical Evidence Based on Effective Tax Rates." Journal of Economic Integration 20 no.3 (2005): 530-542.

Bucovetsky, Sam. "Asymmetric Tax Competition". Journal of Urban Economics 30 (1991): 167-181.

Bucovetsky, Sam. “An Index of Capital Tax Competition.” International Tax and Public Finance 16 no.6 (2009): 727-752.

Damania, Richard, Fredriksson, Per and List, John. “The Multiplier Effect of Globalization.” Economic Letters 83 (2003): 285-292.

Edwards, Jeremy and Keen, Michael. "Tax Competition and Leviathan.” European Economic Review 40 no.1 (1996): 113-134.

Forslid, Rikard. "Tax Competition and Agglomeration: Main Effects and Empirical Implications." Swedish Economic Policy Review 12 (2005): 113-137.

Fuest, Clemens, Bernd, Huber and Mintz, Jack. Capital Mobility and Tax Competition. Boston: New Publishers. 2005.

Garrett, G. "Capital Mobility, Trade and Domestic Politics of Economic Policy." International Organization 49 no.4 (1995): 657-687.

Jacobs, Jan, Ligthart, Jenny and Vrijburg, Henrik. "Consumption Tax Competition Among Governments: Evidence from the United States." International Tax and 
Public Finance 17 no.3 (2010): 271-294.

Keynes, John. General Theory of Employment, Interest and Money. New Dehli: Atlantic Publishers and Distributions. 2008.

Klick, Jonathan and Parisi, Francesco. "Intra-Jurisdiction Tax Competition." Constitutional Political Economy 16 (2005): 387-395.

Leontief, Wassily. "Quantitive Input and Output Relations in Economic System of the United States." Review of Economics and Statistics 18 no.3 (1936): 105-125.

Ludema, Rodney and Wooton, Jan. "Economic Geography and the Fiscal Effects of Regional Integration." Journal of International Economics 52 no.2 (2000): 331-357.

Mendoza E., Razin, A. and. Tesar, L. "Effective tax Rates in Macroeconomics. CrossCountry Estimates of Tax Rates on Factor Incomes and Consumption." Journal of Monetary Economics 34 (1994): 297-323.

Metzler, Lloyd. "Taxes and Subsides in Leontief's Input-Output Model." The Quarterly Journal of Economics 65 no.3 (1951): 433-438.

Miyazava, K. "Internal and External Multipliers in the Input-Output Model." Hitotsubashi Journal of Economics 7 (1996): 38-55.

Sinn, Haus-Werner. "Tax Harmonization and Tax Competition in Europe." European Economic Review 34 (1990): 489-504.

Stauvermann, Peter and Kumar, Ronald. "The Dilemma of International Capital Tax Competition in the Presence of Public Capital and Endogenous Growth." Annals of Economics and Finance 16 no.2 (2015): 255-272.

Swenson, Charles and Moore, Michael. "Use of Input-Output Analysis in Tax Research." Advances in Taxation 1 (1987): 49-83.

Wildasin, David. "Nash Equilibria in Models of Fiscal Competition." Journal of Public Economics 35 (1988): 229-240.

Wilson, John Douglas. “A Theory of Interregional Tax Competition." Journal of 
Urban Economics 19 no.3 (1986): 296-315.

Wilson, John Douglas. “Theories of Tax Competition.” National Tax Journal 52 no.2 (1999): 269-303.

Wilson, John and Wildasin, David. "Capital Tax Competition: Bane or Boon.” Journal of Public Economics 88 (2004): 1065-1091.

Zodrow, George, Mieszkowski, Peter. "Pigou, Tiebout, Property Taxation, and the Underprovision of Local Public Goods." Journal of Urban Economics 19 (1986): 356370.

Zodrow, George. "Capital Mobility and Capital Tax Competition." National Tax Journal 63 no.4 (2010): 861-901. 